\title{
Bernard VALETTE
}

\section{Lumière du rat : vers la maîtrise du Vide}

Il peut paraitre surprenant de placer sous le signe du vide un roman dont l'écriture paradoxale, le flamboiement, l'art de la pointe sensible dès le titre, évoquent plutôt la saturation lyrique ou encore cet excès «baroquisant» auquel le style de Patrick Grainville serait immédiatement reconnaissable. Pourtant, au-delà de l'impression de trop-plein, c'est bien au vertige du vide que le lecteur se trouve confronté, sous le ténébreux éclairage que projette Lumière du rat. Il s'agit tantôt du sentiment de vacuité que donnent les occupations ou l'inoccupation - des protagonistes, tantôt du besoin de viduité qu'appelle par contrecoup la tragique liturgie des repas dominicaux, ou bien encore de l'écœurement engendré par la vanité même de la vie. Vie soumise aux appétits égoïstes, au déferlement de la violence, à la destruction, à l'abandon.

Le vide étend son emprise sur la totalité de l'espace romanesque. Dans un univers semi-abstrait, les tours de banlieue délimitent le royaume des pauvres. Une urbanisation schizoïde oppose les zones pavillonnaires aux villas des bourgeois. À l'horizon, comme un ailleurs incertain, «le Quartier de la Défense prend des allures de banquise dans un naufrage blanc» (p. 237). Voilà le monde de Clotilde (peut-on dire de l'héroïne?), étudiante en Lettres qui s'échappe par le rêve dans un autre monde dominé par un idéal de pureté. Elle travaille sur Mallarmé; la danse classique, qui lui impose une discipline drastique, lui permet de sublimer la pesanteur du corps; surtout, une photo d'Helmut Newton découverte dans un magazine l'obsède: l'image inaccessible d'une énigmatique « Nora » entièrement nue, d'une beauté impeccable, tenant à la main un gigantesque couteau. Tel est le territoire imaginaire de Clotilde, tels sont quelques-uns de ses fantasmes, qui la délivrent du mal, du quotidien, de sa jeune sœur, Armelle, toujours prête à jouir, à se vautrer dans le cloaque des repas familiaux. Le livre s'ouvre sur une scène de préparatifs culinaires où le dégoût de la chair rejoint le déni du sexe. Un poulet décapité, éviscéré, 
farci par les mains expertes de sa mère et de sa sœur devient inévitablement, aux yeux de Clotilde, la métaphore de cette béance féminine qu'elle rejette de toutes ses forces, deux visions se télescopant, celle de la fornication et celle, non moins odieuse, de la parturition : «Tout à l'heure, Clotilde les avait vues préparer la volaille. Fouiller l'énorme fosse de l'oiseau vidé. » (p. 7) Cependant, la présence ponctuelle de Dante jette sur tout le livre un éclairage cru.

Prisonnier du labyrinthe qu'a construit pour lui un zoologiste pervers qui lui voue un attachement haineux, Dante est un rat surdoué. Ce rat pourrait être le véritable héros du livre, dont il justifie le titre. Objet de la narration, il est d'abord maintenu dans une cage aux dimensions fantastiques et aux mécanismes complexes. Son geôlier n'est autre que le père de Carine, voisine et amie de Clotilde. De toute évidence, cette jeune femme libérée et rebelle la fascine. Moins que Dante sans doute, qui suscite, lui, un véritable effroi. De sa prison qui s'inverse en une sorte de mirador panoptique, il observe, scrute, juge ses semblables: les êtres humains. Ce regard n'est-il pas celui de l'auteur lui-même? Son statut, cependant, demeure ambigu. Lorsque les portes de sa cage lui seront ouvertes, il sera à la fois spectateur et acteur, participant à une sorte de rituel orgiaque au cours duquel la cruauté de la nature se confondra avec les pulsions d'Armelle livrée à la bestialité de Jérôme, l'amant en titre de Carine. Rut cosmique qui culminera en une succession de spectacles apocalyptiques mêlant hallucination et lucidité. Le cauchemar qu'il donne à voir est terrifiant, mais il n'est pas fondamentalement différent des représentations mentales qui hantent Clotilde. Mélancolique, derrière la surabondance de la végétation, derrière l'outrance d'un printemps précoce, elle ne peut s'empêcher de songer à la perte, à la disparition, à la souffrance : «Il sembla à la jeune fille que leur [les magnolias] floraison rare et splendide était vouée au supplice, à l'oubli.» (p. 77) L'amour lui apparait comme un viol, un carnage. Alors qu'Armelle s'offre avec un égal enthousiasme aux mâles qui la prennent, à l'eau, au soleil aux éléments, Clotilde a peur de sa propre nudité. Pour autant, elle n'est pas indifférente à la volupté, mais son érotisme ne peut s'épanouir que dans un monde virtuel, celui des nus sur papier glacé que mettent en scène les photographies d'Helmut Newton. Dans ces conditions, que Dante soit finalement massacré, 
dépecé, passé au four et servi à ses parents par Clotilde, a valeur de symbole. Une fois anéantie, cette instance surmoïque lui offrira peutêtre la possibilité d'une libération.

L'itinéraire de Clotilde, entièrement lié à la crise qu'elle traverse alors qu'elle a vingt ans, illustre la guerre apparemment indépassable que se livrent en elle des forces opposées, des aspirations chimériques, une volonté indécise. Le couple vide/plein résume les mille contradictions que cette jeune fille pudique doit affronter, et qui la bloquent, tout en étant la condition d'un éventuel dépassement. Sans qu'elle en ait forcément conscience, Clotilde s'est construite à partir de l'horreur inspirée par la réplétion dévote de ses parents, par la glu familiale. La cérémonie du repas, qu'il s'agisse du déjeuner du dimanche ou du repas d'anniversaire, apparaît comme emblématique de tous les excès, de toutes les abjections que sa nature de prédateur impose à la condition de l'homme. D'emblée, se donnent ainsi à lire les signes de l'obscène. L'activité sexuelle, ou plutôt l'activisme incontrôlable des divers personnages ne fera que les reproduire à satiété : sexualité débridée d'Armelle, la sœur de seize ans, sexualité exhibitionniste de Carine, qui habite la maison voisine, bisexualité de Fabrice et Salah, les partenaires occasionnels. Face à la surenchère pornographique, à la multiplication des scènes d'accouplement, à l'étalage d'une sensualité animale qui l'épouvante, c'est malgré elle que Clotilde se trouve en situation de voyeur. Et toujours, révulsée, elle cherche à fuir cette accumulation de chairs, de nourriture - autant dire de pourriture cette succion de la matière, cette vie pléthorique. Les mesures contraphobiques, on l'a vu, sont nombreuses: ascèse de la chorégraphie, refuge dans la rêverie, culte d'un modèle mythique, Nora, «la jeune Louve. La préférée. La Chasseresse immaculée » (p. 126). L'allusion à Diane, déesse de la chasteté, permet de transposer la nécessité en vertu : vierge par inhibition plus que par choix, Clotilde rejoint du moins l'icône à laquelle elle s'identifie. Comme l'être s'oppose à l'avoir, l'expérience du vide sert ainsi d'antidote, volontairement ou non, à la tyrannie du plein, ce Plein qui aura longtemps été incarné par la sœur cadette, Armelle la dévoreuse, la jouisseuse, la voyageuse insatiable. 
Ne serait-il resté pour la sœur aînée que les miettes du festin? Il ne semble pas. Le renversement final fait apparaitre la fêlure qui est à l'origine du tempérament fugueur d'Armelle, mais aussi de la dépression qui l'entraîne. Les promesses d'avenir sont désormais du côté de Clotilde, bénéficiaire de la lumière portée par le rat, au-delà même de son existence physique. Alors que le plein recherché pour lui-même est illusion, les prémices de la plénitude ne peuvent naître que dans la maîtrise du Vide.

Référence : Patrick Grainville, Lumière du rat, Paris, Seuil, 2008, $76 \mathrm{p}$. 